\title{
XXXVI. Chemical examination of palm oil and cacao butter
}

\author{
John Stenhouse Esq.
}

To cite this article: John Stenhouse Esq. (1841) XXXVI. Chemical examination of palm oil and cacao butter , Philosophical Magazine, 18:116, 186-192, DOI: 10.1080/14786444108650277

To link to this article: http://dx.doi.org/10.1080/14786444108650277

曲 Published online: 01 Jun 2009.

Submit your article to this journal 지

Џll Article views: 2

Q View related articles $\sqsubset$ 
This gives the formula

$$
\begin{aligned}
& \text { Carbon ........... } 35=2675 \cdot 225 \\
& \text { Hydrogen ........ } 56=34.9 \cdot 426 \\
& \text { Oxygen ........... } 1=100 \cdot 000 \\
& 3124 \cdot 651 .
\end{aligned}
$$

It is somewhat singular that this is precisely the composition which Dr. Kane found for the oil of Mentha viridis.

\section{Chemical Examination of Palm Oil and Cacao Butter. By John Stenhouse, Esq.* \\ Palm Oil.}

THIS oil has of late years become rather an important article of commerce, from the great extent to which it is employed in the manufacture of soap. It is chiefly imported from the coast of Africa, and is derived, according to some botanists, from the Cocus Butyracea, according to others from the Avoira Elais. It is extracted by boiling the bruised fruit in water ; the oil collects as a cake on the surface, from which it is easily removed. It has a butyraceous consistence, is of a reddish yellow colour, and has an agreeable aromatic odour. When long kept it becomes readily rancid, and whitens at the same time, especially if exposed to the influence of the light and air. Soap made with the unbleached oil is of a yellow colour, but white soap may be made from it if the oil has been previously bleached. This may be done in various ways; by melting the oil in hot water and treating it with peroxide of manganese and sulphuric acid, or by keeping it melted, spread out in thin layers on iron plates. It has also been proposed to bleach it with hypochlorite of lime and dilute sulphuric acid; and bichromate of potash and muriatic acid have more recently been employed for the same purpose.

It was first observed by Zier, and the observation has been since confirmed by Messis. Pelouze and Boudet, that palm oil is strongly acid, and that its acidity increases with the age of the oil. The quantity of free acid it contains is very great, often amounting to nearly a third of its weight. It is owing to this circumstance that palm oil is so remarkably easily saponifiable. Indeed, a very tolerable soap may be made from it by boiling it for a short time with the alkaline carbonates. Soap made from palm oil and soda is of a firm consistence, has an aromatic odour, and forms an excellent and agreeable detergent. The

* Communicated by the Author. 
greater portion of the common brown soap made in Great Britain contains no tallow at all, but consists of a mixture of palm oil and common resin. The melting point of the specimen of palm oil I examined was $99^{\circ} \mathrm{Fahr}$. It appeared to be pretty old. Palm oil was formerly supposed to contain margaric and oleic acids; but $\mathrm{Mr}$. Fremy has lately subjected it to examination, and found it to contain a new acid, to which he has given the name of the palmitic. I am happy in being able to confirm the truth of his observations.

The mode of proceeding to examine the constituents of palm oil is to saponify it with caustic potash or soda, and then to decompose the soap with muriatic or tartaric acid. The mixture of palmitic and oleic acids thus obtained, is to be dissolved in boiling spirits of wine, in which it is very soluble, and allowed to crystallize. The crystals are to be collected and strongly pressed between folds of blotting paper, and again dissolved in alcohol. These operations are to be repeated eight or nine times till the palmitic acid crystallizes quite free from the oleic acid, which remains dissolved in the mother liquors. Before being subjected to analysis it was once more saponified, and the soap decomposed by muriatic acid. The palmitic acid had then a melting point of $140^{\circ} \mathrm{Fahr}$. The following are the results of its analyses.

gramme.

I. 0.3025 gave 0.827 carbonic acid, and 0.338 water.

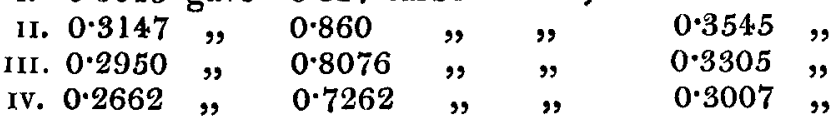

This is per cent.

\begin{tabular}{ccccc} 
& I. & II. & III. & IV. \\
Carbon ... & 75.48 & 75.56 & 75.69 & 75.46 \\
Hydrogen & 12.41 & 12.51 & 12.48 & 12.51 \\
Oxygen. .. & 12.11 & 11.93 & 11.83 & 11.83 \\
\cline { 2 - 4 } & & & & \\
100.00 & 100.00 & 100.00 & 100.00
\end{tabular}

In order to determine the atomic weight of the acid the silver salt was prepared by precipitating an alcoholic solution of the soda soap with nitrate of silver.

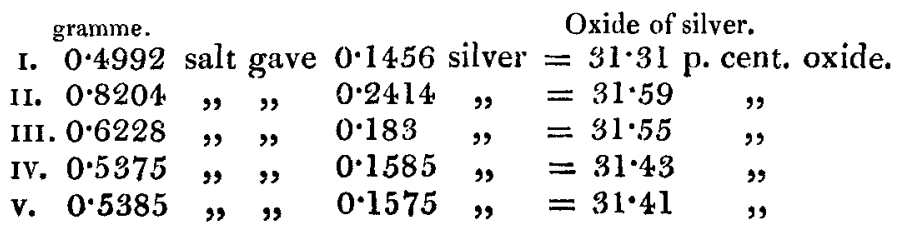


Combustion with oxide of copper gave the following results:

I. 0.3205 salt gave 0.621 carbonic acid and 0.249 water.
II. $0.3305 "$ " 0.6395
III. $0.2885, ", \quad 0.559$
$"$ " "
0.257,
0.222,

\begin{tabular}{|c|c|c|c|}
\hline & I. & II. & $\begin{array}{l}\text { III. } \\
53.58\end{array}$ \\
\hline Carbon ............. & 53.57 & $53 \cdot 50$ & 53.58 \\
\hline Hydrogen.......... & $8 \cdot 63$ & $8 \cdot 64$ & $8 \cdot 54$ \\
\hline Oxygen.............. & $6 \cdot 35$ & $6 \cdot 41$ & $6 \cdot 4 \cdot 3$ \\
\hline Oxide of silver... & $31 \cdot 45$ & $31 \cdot 45$ & $31 \cdot 45$ \\
\hline & $100^{\circ} 0$ & $100 \cdot 00$ & $100 \cdot 00$ \\
\hline
\end{tabular}

The analyses of the hydrate agree best with the following formula :

$$
\begin{aligned}
& 66 \text { atoms of Carbon ...... 5044 } \\
& 128 \text { " Hydrogen ... 824 } \\
& 8, \quad \text { Oxygen ...... } 800 \quad 12 \cdot 00 \\
& 6668 \quad 100 \cdot 00
\end{aligned}
$$

From the determination of the quantity of oxide of silver in the silver salt, however, I am disposed to prefer Mr. Fremy's formula for the hydrate as the more probable. It is

$$
\begin{array}{rrrr}
32 & \text { atoms of Carbon...... } & 2446 \\
64 & \text { Hydrogen... } & 399 \\
4 & \text { Oxygen...... } & 400 \\
\cline { 3 - 4 } & & & 3245
\end{array}
$$

Per cent.

$75 \cdot 37$

$12 \cdot 40$

$12 \cdot 23$

$$
100 \cdot 00
$$

The formula $\mathrm{C}_{32} \mathrm{H}_{62} \mathrm{O}_{3}+\mathrm{Ag} \mathrm{O}$ gives the following numbers for the silver salt:

$$
\begin{array}{rrrrr}
32 & \text { atoms of Carbon......... } & 2446 & 53 \cdot 35 \\
62 & \Rightarrow & \text { Hydrogen...... } & 387 & 3 \cdot 44 \\
3 & \text { Oxygen......... } & 300 & 6 \cdot 54 \\
1 & \Rightarrow & \text { Oxide of silver } & 1452 & 31 \cdot 67 \\
\cline { 3 - 4 } & & \frac{4585}{100 \cdot 00}
\end{array}
$$

The hypothetical composition of the anbydrous acid is consequently as follows :

$$
\begin{aligned}
& 32 \text { atoms of Carbon...... 24.46 } \quad \text { Pr c.08 } \\
& 62 \text { "Hydrogen.. } 387 \quad 12.35 \\
& \begin{array}{lllll}
3 & \quad \text { Oxygen .... } & 300 & 9.57
\end{array} \\
& 3133 \quad 100 \cdot 00
\end{aligned}
$$

The number 3133 agrees very nearly with the mean of five determinations of the silver salt, which gave 3165 for the 
atomic weight of the anhydrous acid. The baryta salt was prepared in the usual way by precipitating an alcoholic solution of the soda soap with chloride of barium.

x. 0.5080 salt gave 0.150 carb. of baryta $=22.90$

II. $0.4947, " 0.1462, ", \quad=22.92$

The calculated quantity is 23.39 per cent. baryta. The atomic weight 3221 , which this gives for the anbydrous acid, does not differ essentially from that found by the silver salt.

The following is the mode of preparing Palmitin, the compound of palmitic acid and glycerine. Palm oil is to be subjected to pressure between folds of linen, to separate the more fluid portion. The solid part is to be treated six or seven times with boiling spirits of wine to remove the palmitic and oleic acids, which are very soluble in that liquid. Palmitin, which, on the contrary, is nearly insoluble in hot spirits of wine, is to be then dissolved in hot æther and filtered, to separate it from the impurities which accompany it, and which remain on the filter. On the cooling of the solution the palmitin is deposited in very small crystals. These are to be pressed between folds of blotting-paper and recrystallized out of æther. These operations are to be repeated six or seven times till the palmitin is free from every trace of olein. It is then to be kept melted on the water-bath till the æther is driven off. Pure palmitin melts at $120^{\circ} \mathrm{Fahr}$, and when saponified yields palmitic acid with the ordinary melting point of $140^{\circ} \mathrm{Fahr}$. Palmitin is quite neutral; on being melted and not allowed to cool it does not crystallize, but forms a half transparent mass like white wax, but which differs from wax in being easily reducible to powder. It is almost insoluble in ordinary spirits; but absolute alcohol dissolves a little of it at a boiling temperature, which precipitates in white flocks on the cooling of the liquid. It is soluble in æther in every proportion. In its appearance and properties generally it very much resembles stearin; palm oil contains only a few parts per cent. of palmitin.

The following are the results of its analysis.

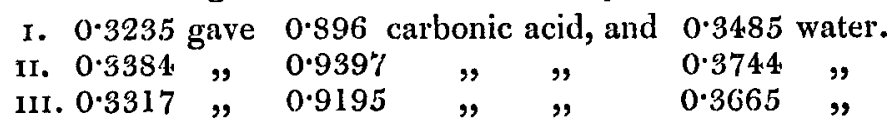
or per cent.

\begin{tabular}{|c|c|c|c|}
\hline Cäbon .............. & $\begin{array}{c}\mathrm{I} \\
76 \cdot 58\end{array}$ & $\begin{array}{c}\text { II. } \\
76 \cdot 78\end{array}$ & $\begin{array}{c}\text { III. } \\
76 \cdot 65\end{array}$ \\
\hline Hydrogen .......... & $11 \cdot 99$ & $12 \cdot 29$ & $12 \cdot 27$ \\
\hline $\mathrm{Ox}$ & $11 \cdot 43$ & $10 \cdot 93$ & $11 \cdot 08$ \\
\hline & $100 \cdot 00$ & $100 \cdot 00$ & $100 \cdot 00$ \\
\hline
\end{tabular}


The calculated numbers are,

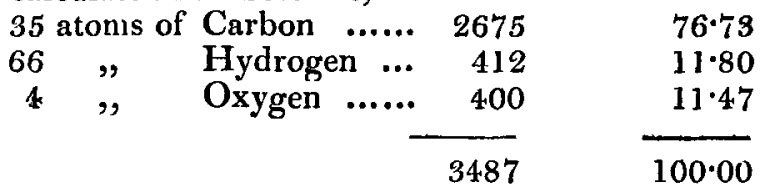

and consequently palmitin must be regarded as consisting of

$$
\begin{aligned}
\mathbf{l} \text { atom of Palmitic Acid } & =\mathrm{C}_{32} \mathbf{H}_{62} \mathrm{O}_{3} \\
1 \text { " } & =\mathrm{C}_{3} \mathbf{H}_{4} \mathrm{O}^{\prime} \\
\mathbf{1} \text { atom of Palmitin } & =\mathrm{C}_{35} \mathbf{H}_{66} \mathrm{O}_{4}
\end{aligned}
$$

It is evident that this gives a very different formula for glycerine from the urdinary one, $\mathrm{C}_{6} \mathrm{H}_{14} \mathrm{O}_{5}$. This, however, gives a much simpler view of its constitution, proving it to belong to the class of simple organic oxides, like those of ethule and methule. This formula also affords a very simple explanation of the decomposition which glycerine undergoes when treated with peroxide of manganese and sulphuric acid. It is then, as is well known, converted into formic and carbonic acids, as under :

$$
\mathrm{C}_{3} \mathrm{H}_{4} \mathrm{O}+\mathrm{O}_{5}=\mathrm{C}_{2} \mathrm{H}_{2} \mathrm{O}_{3}+\mathrm{H}_{2} \mathrm{O}+\mathrm{CO}_{2} \text {. }
$$

Palmitin when distilled gave acrolein, but no sebacic acid; palm oil, on the contrary, when subjected to distillation, yielded sebacic acid in abundance. This shows that the other acid which palm oil contains is the oleic, as it is the only fat acid known to yield sebacic acid by distillation.

Messrs. Pelouze and Boudet discovered that palm oil contains free glycerine, which can be obtained from it by treating the vil with hot water and filtering. I have also succeeded in obtaining it by this process. The acid which accompanied it was neutralized with carbonate of soda, and the glycerine extracted by alcohol. Its quantity was very inconsiderable. The presence of free glycerine in palm oil is what might have been expected from its containing so large a quantity of free palmitic and oleic acids.

Palm oil also contains small quantities of a blueish-green colouring matter. It is heavier than the oil, and forms a thinnish layer, which adheres to the lower part of the cake which palm oil forms when it is melted in water and allowed to cool; I thought at first it was owing to the palm oil having been prepared in copper vessels, but on examination I found that it was wholly of a vegetable nature. Hydrosulphate of ammonia had no effect upon it; caustic alkalies rendered it colourless; muriatic and nitric acid had a similar effect, but sulphuric acid blackened and apparently charred it. 
Butter of Cacao.-Cacao butter is obtained from chocolate beans, the fruit of the Theombra Cacao; either by subjecting the bruised beans to pressure between hot iron plates, or by boiling them in water and scumming off the oil as it collects on the surface. One pound of beans usually yields from three to four ounces of the oil. When first prepared it has usually a yellowish colour, but this can be easily removed by boiling it with water, or still more completely by treating it with hot alcohol. The taste of cacao butter is mild and agreeable; and its smell, which resembles that of the beans, is owing to the presence of an oily matter, which may be easily removed by one or two digestions with alcohol. With caustic soda cacao butter forms an excellent soap; but it is by no means very easily saponified. The melting point of cacao butter is stated by most chemical authors at $122^{\circ} \mathrm{Fahr}$. I found that of the specimen I examined only $86^{\circ}$ Fahr. MM. Pelouze and Boudet state it at $85^{\circ} \mathrm{Fahr}$. Cacao butter is remarkable for the length of time it may be kept without becoming rancid.

In order to subject the acids which cacao butter contains to examination, it was saponified by caustic potash and the soap decomposed by muriatic acid. 'The melting point of the mixed acid was $125^{\circ}$ Fahr.; they were then dissolved in hot spirits of wine and allowed to crystallize, when the crystals were collected and carefully dried by pressure. These solutions and crystallizations were repeated nine or ten times to free them from the less crystallizable acids, which remained dissolved in the alcoholic mother liquors. The crystals had then a melting point of $157^{\circ}$ Fahr., and on analysis they proved to be stearic acid. The following are the results.

1. 0.318 gave 0.8835 carbonic acid, and 0.3622 water.

$\begin{array}{cccccc}\text { II. } 0.2595 & =0.719 \quad, & , & 0.300 & , \\ \text { III. } 0.299 \quad " & 0.832 \quad " & , & 0.347 \quad,\end{array}$
or pei cent.

\begin{tabular}{|c|c|c|c|}
\hline & I. & II. & III. \\
\hline Carbon ....... & $76 \cdot 82$ & $76 \cdot 61$ & $76 \cdot 85$ \\
\hline Hydrogen ... & $12 \cdot 65$ & $12 \cdot 84$ & $12 \cdot 86$ \\
\hline & 10.52 & $10 \cdot 55$ & $10 \cdot 29$ \\
\hline & .00 & $100 \cdot 00$ & 0.00 \\
\hline
\end{tabular}

This gives the following formula for the hydrous acid:

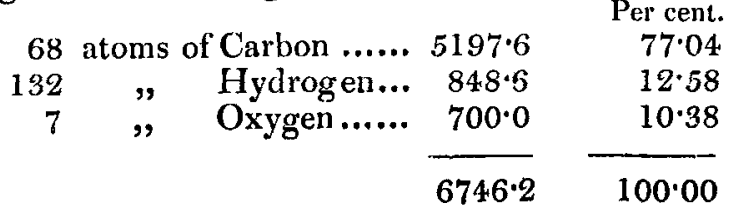




\section{Chemical Examination of Palm Oil and Cacao Butter.}

In order to determine the atomic weight of the acid the æether wasprepared in the usual way, by dissolving a portion of stearic acid in alcohol and saturating it with muriatic acid gas.

The æther is a semi-transparent crystalline body, very like stearin. It was repeatedly washed with hot water to free it from muriatic acid. It was then carefully dried and subjected to analysis; the following are the results.

I. 0.2715 gave 0.7595 carbonic acid, and 0.3155 water.

II. $0.240 " 0.671 \quad, \quad, \quad 0.2805$ " or per cent.

\begin{tabular}{lrr} 
Carbon ............ & \multicolumn{1}{c}{ 1. } & \multicolumn{1}{c}{ 11. } \\
Hydrogen......... & $12 \cdot 35$ & $77 \cdot 30$ \\
Oxygen........... & $9 \cdot 79$ & $12 \cdot 94$ \\
& $100 \cdot 00$ & $9 \cdot 76$ \\
\cline { 2 - 3 } & & $100 \cdot 00$
\end{tabular}

The formula deducible from these analyses, $\mathrm{C}_{72} \mathrm{H}_{144} \mathrm{O}_{7}$, is equivalent to 1 atom acid, 1 atom æether, and 1 atom water.

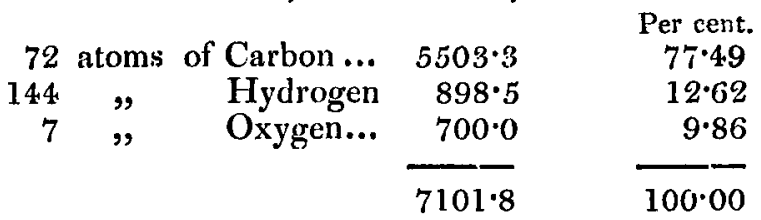

When one atom of æther and one of water are subtracted from the above,

we obtain the numbers

$$
\begin{array}{r}
\mathrm{C}_{72} \mathrm{H}_{144} \mathrm{O}_{7} \\
-\mathrm{C}_{4} \mathrm{H}_{12} \mathrm{O}_{2} \\
\hline \mathrm{C}_{68} \mathrm{H}_{132} \mathrm{O}_{5}
\end{array}
$$

as the formula of anhydrous stearic acid:

$$
\begin{array}{ccccc}
68 \text { atoms of } & \text { Carbon .......... } 5197 \cdot 7 & 79 \cdot 70 \\
132 & \text { Hydrogen...... } & 823 \cdot 6 & 12 \cdot 58 \\
5 & \# & \text { Oxygen ...... } & 500 \cdot 0 & 10 \cdot 38 \\
\hline & & & & 100 \cdot 00
\end{array}
$$

When cacao butter is distilled it yields no appreciable quantity of sebacic acid, but when the uncrystallizable acid which remains in the alcohol out of which the stearic acid has crystallized is subjected to distillation, traces of sebacic acid are readily obtained. This indicates that the quantity of oleic acid contained in cacao butter is by no means very considerable.

I have every reason to believe that besides the stearic and oleic acids, cacao butter contains a third acid, which has a melting point of about $14.0^{\circ} \mathrm{Fahr}$., and which may probably be the margaric.? Its nature, however, must be the subject of some future investigation. 